This is the Author Accepted Manuscript of an article: Samuli Kangaslampi, Aino Hausen \& Tarina Rauteenmaa (2020): Mystical Experiences in Retrospective Reports of First Times Using a Psychedelic in Finland, Journal of Psychoactive Drugs. Published online 08 Jun 2020 by Taylor \& Francis. The final version available at: https://doi.org/10.1080/02791072.2020.1767321.

\title{
Mystical experiences in retrospective reports of first times using a psychedelic in Finland
}

Samuli Kangaslampi ${ }^{1 \mathrm{a}}$, Aino Hausen ${ }^{\mathrm{a}}, \&$ Tarina Rauteenmaa ${ }^{\mathrm{a}}$

${ }^{1}$ ORCiD 0000-0002-0480-9806

${ }^{a}$ Faculty of Social Sciences / Psychology, Tampere University, Finland

Corresponding author: Samuli Kangaslampi, Faculty of Social Sciences / Psychology, FI-33014, Tampere University, Finland. Email: samuli@kangaslampi.net 


\begin{abstract}
Despite their acutely inebriating and sometimes unpleasant effects, some people report positive changes in life satisfaction, well-being, or mental health after taking psychedelic drugs. One explanation may be the ability of psychedelics to trigger mystical-type experiences. We examined the validity, reliability, and factor structure of a novel Finnish translation of the Revised Mystical Experiences Questionnaire (MEQ30) among 288 people retrospectively reporting on their first time using a psychedelic. We found evidence for internal consistency reliability and preliminary evidence for criterion and discriminant validity of the Finnish MEQ30. A four-factor structure with factors for mystical qualities, positive mood, transcendence, and ineffability had the best, fair to reasonable fit to the data. MEQ30 scores and having a full mystical experience were highly associated with describing the experience as mystical, spiritual, or religious, and as personally significant, and somewhat associated with the experience being sad or difficult. Mystical experiences were especially associated with positive changes in relationships with nature and oneself and in creativity. Mystical experiences were more common with larger doses. Increasing research suggests mystical-type experiences to relate to positive changes after taking psychedelics. The Finnish MEQ30 is able to tap into relevant information about this aspect of people's psychedelic experiences.
\end{abstract}

Keywords: psychedelics; psilocybin; LSD; mystical experience; well-being 


\section{INTRODUCTION}

During their acute effects, classic psychedelic drugs cause marked changes in perception, cognition, mood, and experience of self. They hamper cognitive functioning in areas such as attention (Hasler et al. 2004), decision-making (Kometer et al. 2012), as well as time perception and working memory (Wittmann et al. 2007). Their effects are often described as positive and uplifting, but can also be experienced as difficult, frightening, and uncomfortable (Carbonaro et al. 2016; Hasler et al. 2004; Griffiths et al. 2006; Strassman 1984). Despite the acute inebriating effects of psychedelics, evidence from both naturalistic studies and controlled experiments suggests possible positive long-term effects on well-being (Bouso et al. 2012; Schmid and Liechti 2018), mood, attitude, and behavior (Griffiths et al. 2008, 2011, 2018), mental health (Davis et al. 2019; Hendricks et al. 2015; Krebs and Johansen 2013; Johansen and Krebs 2015; Uthaug et al. 2019), as well as aesthetic experience and relationship with the environment (Studerus et al. 2011). Pilot studies indicate psychedelics may also hold promise in the treatment of clinical-level depression, anxiety, or addictions (Bogenschutz et al. 2015; Carhart-Harris et al. 2018; Gasser, Kirchner, and Passie 2014; Griffiths et al. 2016; Grob et al. 2011; Palhano-Fontes et al. 2019; Ross et al. 2016). These puzzling and seemingly contradictory effects of psychedelics (CarhartHarris, Kaelen, and Bolstridge 2016) have prompted several explanations for what may lie behind their potential for long-term positive change in some users. One prominent explanation is the ability of psychedelic drugs to occasion in a significant share of users a mystical experience similar to those described to occur spontaneously among religious mystics or meditators (Griffiths et al. 2006, 2011; Pahnke 1963). Such mystical experiences have been found to associate with and explain some of the improvements resulting from psychologically supported sessions with psychedelics in anxiety and 
depressive symptoms (Griffiths et al. 2016; Roseman, Nutt, and Carhart-Harris 2018; Ross et al. 2016), success in smoking cessation (Garcia-Romeu, Griffiths, and Johnson 2015), reduction in alcohol use (Bogenchutz et al. 2015), increases in openness (MacLean, Johnson, and Griffiths 2011), and positive changes in attitudes, mood, and behavior (Griffiths et al. 2011).

Though mystical experiences are difficult to describe in words, and thus to categorize, measure or quantify, some instruments have been developed and used to study them. Pahnke (1969) introduced the 43-item Mystical Experiences Questionnaire (MEQ) covering the dimensions of internal and external unity, transcendence, noetic and sacred qualities, positive mood, and ineffability or paradoxicality. The MEQ has subsequently been used in a number of studies with psychedelics, often combined with distractor items to form the 100-item States of Consciousness Questionnaire (Griffiths et al. 2006, 2008). Based on analyses of retrospective online surveys of mystical experiences occasioned by the use of psilocybin-containing mushrooms, MacLean et al. (2012) developed and psychometrically validated a revised 30-item version of the MEQ, the MEQ30. Factor analyses suggested a four-factor structure with factors corresponding to mystical nature of the experience, positive mood, transcendence of time and space, and ineffability. Studying mystical experiences in controlled psilocybin studies in the laboratory, Barrett, Johnson, and Griffiths (2015) found evidence for the internal and external validity of the MEQ30 and support for the four-factor structure identified by MacLean et al. (2012). They also adapted criteria for the MEQ30 to qualify an experience as a full mystical experience.

As research with psychedelics continues to expand and globalize, validated translations of relevant measures are essential. At the same time, possible cultural and other local differences in the experience of altered states of consciousness and 
mysticism may become apparent. The meaning and consequences of mystical experiences may differ in different contexts and environments.

Here, we study and validate a novel Finnish translation of the MEQ30 among people retrospectively reporting on their first time using a psychedelic. We examine whether the Finnish MEQ30 demonstrates adequate reliability and criterion and discriminant validity. We also assess the extent to which its factor structure corresponds to that reported for the English version. Further, we explore possible links between mystical experiences during first psychedelic experiences and self-reported changes in different facets of well-being experienced afterwards.

\section{METHODS}

\section{Procedure and Participants}

We used a simple online survey tool to prepare a questionnaire to collect the data. On the first page of the questionnaire, we presented the following criteria for participating in the survey: (1) 18 years of age or above; (2) fluent in Finnish; (3) having used a psychedelic at least once; (4) having a good recollection of one's first experience with a psychedelic. The participants were then instructed to think about the first time they ever used a psychedelic when answering the questionnaire.

We shared an invitation to participate in the study containing a link to the questionnaire on numerous Finnish-language Facebook groups related to psychedelics and on public profiles on Facebook and Instagram, from where other users shared it onwards. Answers to the survey were extracted from the survey tool on May 1, 2019. 290 participants responded to the survey between February 25 and April 26, 2019. We manually checked records to identify careless, inappropriate, or automated responses, but detected no evidence of such responding. We excluded the answers of two 
participants. One reported using dextromethorphan, which we did not consider a psychedelic for the purposes of this study. Another participant was unsure of the substance used and whether it was a psychedelic. Our final sample size was thus 288 .

\section{Measures}

Mystical experience. We used a novel Finnish translation of the Revised Mystical Experiences Questionnaire (MEQ30; Barrett, Johnson, and Griffiths 2015) to measure the degree to which the experiences of first-time users of psychedelics included elements of mystical nature. Participants evaluated on a five-point scale $(1=$ none, not at all; 2 = so slight cannot decide; 3 = moderate; 4 = strong (equivalent in degree to any other strong experience); 5 = extreme (more than any other time in my life and stronger than 4)) the degree to which they had experienced each of 30 different phenomena during any time of their session taking psychedelics. We calculated total scores on the MEQ30 by taking the mean of all responses, and subscale scores for the four subscales suggested by MacLean et al. (2012), (1) mystical nature, (2) positive mood, (3) transcendence, and (4) ineffability, by taking the mean of all responses to questions included in the particular subscale. We also divided participants into those who had experienced a full mystical experience and those who had not, following the criteria defined by Barrett, Johnson, and Griffiths (2015). Those who received a mean score of at least three on the scale of $1-5(60 \%$ of maximum points) in each subscale were classified as having undergone a full mystical experience.

We translated the MEQ30 in five steps. First, the second and third authors translated the measure into Finnish. Second, the first author back-translated the translation into English. Third, all authors compared the back-translation and the original English version and discussed the choice of words for items where differences were noted. Fourth, we piloted a preliminary Finnish translation with several outsiders 
with no previous knowledge of the MEQ30 in relation to their experiences with psychedelics. Finally, based on feedback from the pilot, we made a few clarifications to individual items of the questionnaire. The final Finnish version of the MEQ30, MEQ30suomi, is freely available for non-commercial use from the first author and at https://doi.org/10.6084/m9.figshare.12249329.v1.

Quality of the experience. We asked participants to evaluate on a five-point scale $(1=$ not at all, $2=$ slightly, $3=$ somewhat, $4=$ a lot, $5=$ tremendously $)$ the extent to which their experience (1) had included mystical, spiritual, or religious elements; (2) had been personally significant; and (3) had been fun. We further asked the participants to evaluate how difficult or easy their experience had been $(1=$ difficult, $2=$ somewhat difficult, 3 = average, $4=$ easy, $5=$ very easy) and how pleasant their experience had been $(1=$ unpleasant, $2=$ somewhat unpleasant, $3=$ neutral, $4=$ somewhat pleasant, 5 $=$ pleasant .

Changes in well-being. We used a set of eight questions, partly adapted from the Persisting Effects Questionnaire (Griffiths et al. 2011) to assess self-evaluated changes in well-being in the weeks and months following the first use of psychedelics. Participants evaluated on a seven-point scale $(1=$ notably worse than before, $2=$ somewhat worse than before, $3=$ slightly worse than before, $4=$ no change, $5=$ slightly better than before, $6=$ somewhat better than before, $7=$ notably better than before) whether they had experienced changes in eight areas: (1) Well-being and life satisfaction, (2) mental health, (3) physical health, (4) creativity, (5) memory and cognitive skills, (6) their relationship with nature, (7) their relations with others, and (8) their relationship with themselves.

\section{Statistical analyses}

We carried out all data processing and analyses using R 3.2.4. We further used the 
lavaan 0.6-3 (Rosseel 2012) and psych 1.7.8 (Revelle 2017) R packages. Because answering all questions was required to proceed forward in the survey, there were no data missing. R scripts are available upon request from the first author. All collected research data are also freely available for any non-commercial research from the first author upon request.

We assessed the validity and reliability of the Finnish MEQ30 in several ways. We first calculated Cronbach's alpha $(\alpha)$ and MacDonald's hierarchical $\left(\omega_{\mathrm{h}}\right)$ and total omega $\left(\omega_{\text {total }}\right)$ as indicators of internal consistency for subscales and total score on the MEQ30. We then assessed the validity of our translation by looking at bivariate correlations between total scores on the MEQ30 and self-evaluations of whether the experience had included spiritual, religious, or mystical elements and whether it had been personally significant. We compared these correlations to those of MEQ30 total scores with describing the experience as fun, sad, difficult, or pleasant - features that we would not consider as fundamental to a mystical experience. We further compared the mean answers to these questions of those who had experienced a full mystical experience, as indicated by their responses on the MEQ30, with those who had not, using Welch's $t$ tests.

Next, we carried out confirmatory factor analyses with three possible multiplefactor structures as well as a single-factor model for the MEQ30, to examine construct validity of the translation and determine which factor structure would show the best fit. The first potential structure was the four-factor model suggested by previous factor analyses, with Mystical, Positive Mood, Transcendence, and Ineffability factors (Barrett, Johnson, and Griffiths 2015; MacLean et al. 2012). The second structure tested, dubbed the Hood model, was based on factors derived from the Hood Mysticism Scale (Hood 1975), with three factors corresponding to Introvertive, Extrovertive, and 
Interpretation facets of the experience. A third structure, dubbed the Stace model, was a variation of the Hood model, where items relating to ineffability were part of the Interpretation factor, instead of the Introvertive factor. Finally, we tested a single-factor model where all items load onto the same latent mystical experience factor.

As we had Likert-type responses with six alternatives and non-normality in the distribution of responses, we treated responses as ordinal, and used the diagonally weighted least squares mean and variance adjusted estimator (WLSMV) in factor analyses. We report and employ the population-corrected robust CFI, TLI, and RMSEA (Xia 2016), as well as the SRMR, as fit indices. Sample-corrected robust versions of the fit indices would be preferable, but are not yet available in statistical packages, to our knowledge. We use these indices mainly to compare the fit of different models, as exact cut-off criteria for acceptable or good fit have not been established for WLSMV estimation, and cut-offs defined for maximum likelihood estimation are not appropriate (Garrido, Abad, and Ponsoda 2016; Xia 2016). We also carried out similar analyses using maximum likelihood estimation as sensitivity analyses.

Finally, as exploratory analyses, we examined links between mystical experiences and self-evaluated changes in well-being in two ways. First, we again compared the answers to the well-being questions of those who had experienced a full mystical experience with those who had not, using Welch's $t$ tests. Second, we estimated a latent variable model, where a latent mystical experience variable, indicated by factors of the MEQ30 according to the best fitting factor structure, predicted changes in different facets of self-evaluated well-being. Here, we used maximum likelihood estimation with bootstrapped standard errors based on 5000 draws.

We requested informed consent from the participants on the first page of the questionnaire. The collected data did not constitute a register of personal information, as 
defined by the Finnish Office of the Data Protection Ombudsman. The study was exempt from prior external ethical review, as it did not fulfill any of the conditions set by the Human Sciences Ethics Committee of Tampere Region (Tampere University, 2019) for such review, based on the ethical principles of research with human participants of the Finnish National Board on Research Integrity (2019).

[Insert Table 1 here]

\section{RESULTS}

\section{Descriptive Statistics}

Table 1 presents descriptive statistics on our participants and the first time they had used a psychedelic. Our respondents were majority women (56.9\%) and most commonly between $24-29$ years $(34.7 \%)$ or $18-23$ years of age $(26.4 \%)$, with high school or vocational school (43.1\%) or Bachelor's level education (27.4\%). Nearly all had used psychedelics several times, most commonly 11-50 times (42.7\%). Just around one tenth of the participants $(11.5 \%)$ had used psychedelics for the first time in the last year, while most commonly the first experience had occurred $2-5$ years $(35.1 \%)$ or 510 years ago (27.1\%). LSD (44.4\%) and psilocybin or psilocybin-containing mushrooms (46.2\%) were by far the most commonly used psychedelics. For their first experience, most had taken a typical dose $(60.1 \%)$ either at their home $(32.3 \%)$ or a friend's home (33.0\%), with either one other person (36.8\%) or several other familiar people present $(42.4 \%)$.

Mean total score on the MEQ30 was $2.76(S D=1.02)$, or $55.2 \%$ of the maximum total score. Out of 288 participants, 77 (26.7\%) were classified as having had a full mystical experience, receiving a score of three or above on all four subscales of the MEQ30. In comparing those with full mystical experiences and those without in 
terms of demographic variables and contexts of their experiences, significant differences were only observed in the dosage $\left(\chi^{2}(4)=12.35, p=.015\right)$. Leaving out those who were unsure of dosage, more participants with full mystical experiences reported larger than typical or very large doses $(24.7 \%)$ than those without a mystical experience $(13.2 \%)$.

\section{Reliability and validity of the Finnish Revised Mystical Experiences Questionnaire}

Internal consistencies of the suggested subscales of the MEQ30 were good to excellent, $\alpha=.95,95 \%$ CI $[.95, .96], \omega_{\mathrm{h}}=.89, \omega_{\text {total }}=.96$ for Mystical; $\alpha=.80$, CI $[.76, .83], \omega_{\mathrm{h}}=$ $.63, \omega_{\text {total }}=.88$, for Positive; $\alpha=.85$, CI $[.83, .88], \omega_{\mathrm{h}}=.74, \omega_{\text {total }}=.90$, for Transcendence; $\alpha=.79$, CI $[.74, .83], \omega_{\text {total }}=.79$, for Ineffability $\left(\omega_{\mathrm{h}}\right.$ not available for three-item subscale). Internal consistency for the full MEQ30 was excellent, $\alpha=.96, \mathrm{CI}$ $[.95, .96], \omega_{\mathrm{h}}=.88, \omega_{\text {total }}=.97$.

Total scores on the MEQ30 correlated strongly with the extent to which participants considered their experience to have included "spiritual, religious, or mystical features" $(r=.70, p<.0001)$ and with the degree to which they felt the experience had been "personally significant" $(r=.65, p<.0001)$. Correlations between total score on the MEQ30 and the experience being "fun" $(r=.16, p=.006)$, "sad" $(r=$ $.23, \mathrm{p}=.0001)$, or "easy" $(r=-.29, p<.0001)$ were much lower, though still significant. We found no significant correlation between total scores on the MEQ30 and how "pleasant" the participants rated their experience.

[Insert Table 2 here]

As presented in Table 2, those who were classified as having had a full mystical experience reported their experience as having included more mystical or spiritual features, mean answer 4.08 vs. $2.63, t(169.89)=10.02, p<.0001, g=1.19$, more personally significant, 4.79 vs. $4.01, t(277.54)=8.59, \mathrm{p}<.0001, g=0.82$, more sad, 
2.25 vs. $1.84 ; t(115.26)=2.44, p=.0162, g=0.36$, and more difficult, 3.30 vs. 3.78 ;

$t(129.3)=-3.027, p=.00298, g=0.41$. We found no significant difference between the groups in how fun or pleasant they ranked their experiences.

[Insert Table 3 here]

\section{Factor structure of the Finnish Revised Mystical Experiences Questionnaire}

Table 3 presents the fit statistics for the factor structures tested. None of the models appeared a good or excellent fit, but the four-factor model had the best, fair to reasonable, fit according to most of the indices we used.

[Insert Figure 1 here]

Figure 1 presents the results of confirmatory factor analysis with the four-factor model. All standardized loadings were above .50. Items 7 ("Loss of your usual sense of space"), 11 (“Loss of usual awareness of where you were"), and 30 (“Feelings of joy") had the lowest loadings, between .50 and .60 . Sensitivity analyses using robust maximum likelihood estimation, presented in Supplementary Table 1, also indicated that the four-factor model had the best fit, although fit statistics were somewhat poorer using this approach, which assumes endogenous variables to be continuous $\left(\mathrm{CFI}_{\text {robust }}=\right.$ $\left..877 ; \mathrm{TLI}_{\text {robust }}=.866, \mathrm{RMSEA}_{\text {robust }}=.076, \mathrm{SRMR}=.067\right)$.

\section{Mystical experiences and self-evaluated change in well-being}

As shown in Table 2, those with full mystical experiences reported significantly more positive changes in all areas surveyed. The largest differences in scores were observed for changes in one's relationship with nature, 5.99 vs. 5.03, $\mathrm{t}(131.25)=6.87, \mathrm{p}<.0001$, $\mathrm{g}=0.93$, changes in creativity, 5.66 vs. $4.85, \mathrm{t}(117.22)=5.753, \mathrm{p}<.0001, \mathrm{~g}=0.83$, and changes in relationship with self, 5.99 vs. $5.19, \mathrm{t}(135.92)=4.82, \mathrm{p}<.0001, \mathrm{~g}=0.64$. In terms of effect size, differences in changes in cognitive skills and memory were also 
notable, 4.81 vs. $4.15, \mathrm{t}(95.46)=5.01, \mathrm{p}<.0001, \mathrm{~g}=0.84$

In the latent variable model, degree of mystical experience likewise associated with changes in all areas surveyed (all $p \mathrm{~s}<.001$ ). Again, the strongest associations were observed for changes in relationship with nature (fully standardized $\beta=0.61$ ), in relationship with self $(\beta=0.51)$ and in creativity $(\beta=.49)$. The model demonstrated adequate fit to the data $\left(\chi^{2}(26)=80.01, \mathrm{CFI}=.968, \mathrm{TLI}=.920, \mathrm{RMSEA}=.085\right.$, SRMR $=.052$ ). See Supplementary Figure 1 for details.

\section{DISCUSSION}

Our findings provide evidence for internal consistency reliability and preliminary evidence for construct, criterion, and discriminant validity of the Finnish translation of the MEQ30. The four-factor structure suggested for the English version of the scale by earlier research (Barrett, Johnson, and Griffiths 2015; MacLean et al. 2012), with factors corresponding to subscales of Ineffability, Transcendence, Positive Mood, and Mystical Qualities, demonstrated the best, fair to reasonable, fit out of the tested alternatives for the translated measure. We also found internal consistency of the factors and total score to be good to excellent. Further, scores on the MEQ30 correlated strongly with participants' self-evaluations of their first experiences with psychedelics as including mystical, spiritual, or religious elements and of being personally significant. Correlations with the experience being fun, sad, or difficult were also significant, but weaker. Similarly, those who we classified as having had a full mystical experience rated their experience as having included much more mystical, spiritual, or religious elements and having been much more personally significant, somewhat sadder and somewhat more difficult. Although positive mood is considered as one aspect of a mystical experience on the MEQ30, those with a full mystical experience did not differ from others in terms of how "fun" or "pleasant" they rated their experience. Overall, 
these associations tentatively suggest the MEQ30 is able to tap into relevant aspects of mystical-type or peak experiences occasioned by the use of psychedelics in its Finnish translation.

We also examined links between mystical experiences and self-evaluated changes in different areas of well-being in the weeks and months following the participants' first use of psychedelics. Those with full mystical experiences reported more positive changes in all areas surveyed, as compared with those without such an experience. Similarly, across all participants, the overall level of mystical quality of the experience predicted more positive changes in all areas surveyed. These associations were strongest for positive changes in relationship with nature, in relationship with oneself, and in creativity. Our findings are in line with previous research, although most studies have looked at more aggregate measures of positive changes in well-being, life satisfaction, or attitudes (Griffiths et al., 2018; Haijen et al., 2018). Regarding nature relationship specifically, Nour, Evans, and Carhart-Harris (2017) found both lifetime psychedelic use generally and the most intense level mystical-type ego dissolution felt during a psychedelic experience to predict higher nature relatedness in a naturalistic cross-sectional survey. Feelings of connectedness and unity with the world or cosmos during mystical experiences may explain improved and deepened relationship with nature after psychedelic use. As regards creativity, some small studies provide evidence that ayahuasca and psilocybin may improve divergent creative thinking acutely or subacutely, and convergent thinking several days or weeks after ingestion (Kuypers et al. 2016; Mason et al. 2019; Uthaug et al. 2018). It is not clear, however, what role mystical experiences might play in promoting creativity. Our findings about a link might also be explained by the general level of intensity of the experience. Overall, the 
self-evaluated and highly retrospective nature of all these ratings limit the conclusions that can be drawn.

In our sample, those with full mystical experiences reported taking larger doses. This finding agrees with previous studies (e.g., Griffiths et al. 2011; Haijen et al. 2018; Studerus et al. 2011). However, this does not mean "the larger the better" in terms of dosage of psychedelics. Larger doses of psychedelics are also associated with more difficult or challenging experiences, more anxiety, and more acutely impaired cognition (Carbonaro et al. 2016; Griffiths et al. 2011; Haijen et al. 2018; Studerus et al. 2011) and generally intensify all aspects of the experience. We, too, observed a moderate correlation between mystical-type experiences and the difficulty of the experience, possibly explained by the larger doses involved. Clearly, experiences people later judge as valuable may be very intense and demanding, but it remains to be determined whether particularly difficult or challenging psychedelic experiences are more likely to facilitate beneficial changes afterwards (Carbonaro et al. 2016).

Apart from dosage, Haijen et al. (2018) found clear intentions and baseline levels of trait absorption to predict mystical experiences. Studerus et al. (2011) also found absorption, lack of recent psychological problems, and an active, emotionally excitable state prior to intake to predict mystical experiences. Here, we found no differences in demographic factors, the psychedelic used, or location or context of use between those with full mystical experiences and those without. However, the small, self-selected sample precludes any firm conclusions, and we did not assess expectations, intentions, or personality traits.

A minority of our participants could be classified as having undergone a full mystical experience when taking a psychedelic for the first time. Still, average scores we observed on the Finnish MEQ30 were somewhat lower than those seen in previous 
studies using the English (e.g., Griffiths et al., 2016; 2018) and non-validated German versions of the measure (Schmid \& Liechti, 2018). Dosage is likely to explain some of these differences. A quarter of our participants estimated their dose as smaller than average, while all participants in these laboratory studies received average to large doses of psilocybin or LSD. The varied contexts in which our participants took psychedelics were also likely to be less conducive to mystical experiences. It remains to be established whether average ratings tend to be similar using different translations of the measure with similar doses in similar contexts, or whether there might be cultural or translation-related differences that could affect appropriate cut-offs.

We chose to focus on first uses of psychedelics in order to gather a sample with a variety of types of experiences, not just particularly significant or memorable ones. However, this meant that retrospective recall bias is a substantial concern. Specifically, experiences during later use occasions are likely to have influenced memories and interpretations of the first time our participants used a psychedelic. Another limitation is that we did not include a question on the general strength or intensity of the drug experience, as some previous studies have done (e.g., Barrett, Jonhson, and Griffiths 2015). Such a question would help to separate overall intensity of the effect of psychedelics from their ability to occasion mystical experiences. Further, aside from the MEQ30, we inquired about the nature of the experience and self-reported changes afterwards using simple, individual Likert-type questions in novel translations. These questions did not form validated scales. Accordingly, the converging evidence they provide on the criterion and discriminant validity of the Finnish MEQ30 should be considered preliminary. Our sample was small for a validation study, and especially so for the confirmatory factor analysis. The sample was also unlikely to be a representative of users of psychedelics in Finland, as participation was based on personal interest and 
recruitment was through fora devoted to discussion about psychedelics. It is likely that respondents' experiences were overall more positive and/or personally meaningful than typical.

These limitations notwithstanding, the Finnish version of the MEQ30 appears to be a valid and reliable measure of mystical experiences occasioned by the use of psychedelics with adequate psychometric properties. Researchers may collect useful information about participants' experiences by using it in future studies with psychedelics. Increasing research suggests mystical-type experiences may be relevant for the enduring positive changes in areas such as relationship with self and the natural environment that some users report after using psychedelics. Providing a setting conducive to such experiences, whether described as mystical, peak, or emotional breakthrough, is also likely to be of benefit in clinical applications of psychedelics.

\section{Contribution of Authors}

All authors together conceived of and planned the study, translated the measure, and prepared the questionnaire. AH and TR mainly organized data collection and participant recruitment. SK processed the data and carried out statistical analyses. SK wrote the majority of the manuscript with critical input from AH and TR. All authors read and approved the final manuscript.

\section{Author Disclosure}

The authors declare that they have no conflicts of interest. 


\section{References}

Barrett, F. S., M. W. Johnson, and R. R. Griffiths. 2015. Validation of the revised Mystical Experience Questionnaire in experimental sessions with psilocybin. Journal of Psychopharmacology 29(11): 1182-90. doi: $10.1177 / 0269881115609019$

Bogenschutz, M., A. Forcehimes, J. Pommy, C. Wilcox, P. Barbosa, and R. Strassman. 2015. Psilocybin-assisted treatment for alcohol dependence: a proof-of-concept study. Journal of Psychopharmacology 29(3): 289-99. doi: $10.1177 / 0269881114565144$

Bouso J. C., D. González, S. Fondevila, M. Cutchet, X. Fernández, P. C. Ribeiro Barbosa, M. Á. Alcázar-Córcoles, W. S. Araújo, M. J. Barbanoj, et al. 2012 Personality, psychopathology, life attitudes and neuropsychological performance among ritual users of ayahuasca: A longitudinal study. PLOS ONE 7(8): e42421. doi: 10.1371/journal.pone.0042421

Carbonaro, T., M. Bradstreet, F. Barrett, K. MacLean, R. Jesse, M. Johnson, and R. Griffiths. 2016. Survey study of challenging experiences after ingesting psilocybin mushrooms: Acute and enduring positive and negative consequences. Journal of Psychopharmacology 30(12): 1268-78. doi: $10.1177 / 0269881116662634$

Carhart-Harris, R. L., M. Bolstridge, C. M J. Day, J. Rucker, R. Watts, D. E. Erritzoe, M. Kaelen, B. Giribaldi, M. Bloomfield, S. Pilling, et al. 2018. Psilocybin with psychological support for treatment-resistant depression: six-month follow-up. Psychopharmacology 235(2): 399-408. doi: 10.1007/s00213-017-4771-X

Carhart-Harris, R.L., M. Kaelen, M. Bolstridge, T. M. Williams, L. T. Williams, R. Underwood, and D. J. Nutt. 2016. The paradoxical psychological effects of lysergic acid diethylamide (LSD). Psychological Medicine 46(7): 1379-1390. doi: $10.1017 / \mathrm{S} 0033291715002901$

Davis, A. K., S. So, R. Lancelotta, J. P. Barsuglia, and R. R. Griffiths. 2019. 5methoxy-N,N-dimethyltryptamine (5-MeO-DMT) used in a naturalistic group setting is associated with unintended improvements in depression and anxiety. American Journal of Drug and Alcohol Abuse 45(2): 161-9. doi: $10.1080 / 00952990.2018 .1545024$ 
Finnish National Board on Research Integrity. 2019. Finnish National Board on Research Integrity TENK guidelines 2019: The ethical principles of research with human participants and ethical review in the human sciences in Finland. Available at https://tenk.fi/files/Ihmistieteiden_eettisen_ennakkoarvioinnin_ohje_2019.pdf

Garrido, L. E., F. J. Abad, and V. Ponsoda. 2016. Are fit indexes really fit to estimate the number of factors with categorical variables? Some cautionary findings via Monte Carlo simulation. Psychological Methods 21(1): 93-111. doi: $10.1037 /$ met0000064

Gasser, P., K. Kirchner, and T. Passie. 2014. LSD-assisted psychotherapy for anxiety associated with a life-threatening disease: a qualitative study of acute and sustained subjective effects. Journal of Psychopharmacology 29(1): 57-68. doi: $10.1177 / 0269881114555249$

Griffiths, R. R., M. W. Johnson, M. A. Carducci, A. Umbricht, W. A. Richards, B. D. Richards, M. P. Cosimano, and M. A. Klinedinst. 2016. Psilocybin produces substantial and sustained decreases in depression and anxiety in patients with life-threatening cancer: A randomized double-blind trial. Journal of Psychopharmacology 30(12): 1181-97. doi: 10.1177/0269881116675513

Griffiths, R. R., M. W. Johnson, W. A. Richards, B. D. Richards, R. Jesse, K. A. MacLean, F. S. Barrett, M. P. Cosimano, and M. A. Klinedinst. 2018. Psilocybin-occasioned mystical-type experience in combination with meditation and other spiritual practices produces enduring positive changes in psychological functioning and in trait measures of prosocial attitudes and behaviors. Journal of Psychopharmacology 32(1): 49-69. doi: $10.1177 / 0269881117731279$

Griffiths, R. R., M. W. Johnson, W. A. Richards, B. D. Richards, U. McCann, and R. Jesse. 2011. Psilocybin occasioned mystical-type experiences: immediate and persisting dose-related effects. Psychopharmacology 218(4): 649-65. doi: $10.1007 / \mathrm{s} 00213-011-2358-5$

Griffiths, R. R., W. A. Richards, M. W. Johnson, U. McCann, and R. Jesse. 2008. Mystical-type experiences occasioned by psilocybin mediate the attribution of 
personal meaning and spiritual significance 14 months later. Journal of Psychopharmacology 22(6): 621-32. doi: 10.1177/0269881108094300

Griffiths, R. R., W. A. Richards, U. McCann, and R. Jesse. 2006. Psilocybin can occasion mystical-type experiences having substantial and sustained personal meaning and spiritual significance. Psychopharmacology 187(3): 268-83. doi: 10.1007/s00213-006-0457-5

Grob, C. S. , A. L. Danforth, G. S. Chopra, M. Hagerty, C. R. McKay, A. L. Halberstadt, and G. R. Greer. 2011. Pilot study of psilocybin treatment for anxiety in patients with advanced-stage cancer. Archives of General Psychiatry 68(1): 71-8. doi: 10.1001/archgenpsychiatry.2010.116

Haijen, E. C. H. M., M. Kaelen, L. Roseman, C. Timmermann, H. Kettner, S. Russ, D. Nutt, R. E. Daws, A. D. G. Hampshire, R. Lorenz, and R. L. Carhart-Harris. 2018. Predicting responses to psychedelics: A prospective study. Frontiers in Pharmacology 9: 897. doi: 10.3389/fphar.2018.00897

Hasler, F., U. Grimberg, M. A. Benz, T. Huber, and F. X. Vollenweider. 2004. Acute psychological and physiological effects of psilocybin in healthy humans: a double-blind, placebo-controlled dose-effect study. Psychopharmacology 172(2): 145-56. doi: 10.1007/s00213-003-1640-6

Hendricks, P. S., C. B. Thorne, C. B. Clark, D. W. Coombs, and M. W. Johnson. 2015. Classic psychedelic use is associated with reduced psychological distress and suicidality in the United States adult population. Journal of Psychopharmacology 29(3): 280-8. doi: 10.1177/026988111456565

Hood, R.W. 1975. The construction and preliminary validation of a measure of reported mystical experience. Journal for the Scientific Study of Religion 14: 29-41. doi: $10.2307 / 1384454$

Johansen, P.-Ø. and T. S. Krebs. 2015. Psychedelics not linked to mental health problems or suicidal behavior: A population study. Journal of Psychopharmacology 29(3): 270-9. doi: 10.1177/0269881114568039

Krebs, T. S. and P.-Ø. Johansen. 2013. Psychedelics and mental health: A population study. PloS ONE 8(8): e63972. doi: 10.1371/journal.pone.0063972

Kuypers, K. P. C., J. Riba, M. de la Fuente Revenga, S. Barker, E. L. Theunissen, and J. G. Ramaekers. 2016. Ayahuasca enhances creative divergent thinking while decreasing conventional convergent thinking. Psychopharmacology 233(18): 3395-403. doi: 10.1007/s00213-016-4377-8. 
MacLean, K. A., M. W. Johnson, and R. R. Griffiths. 2011. Mystical experiences occasioned by the hallucinogen psilocybin lead to increases in the personality domain of openness. Journal of Psychopharmacology 25(11): 1453-61. doi: $10.1177 / 0269881111420188$

MacLean, K. A., J.-M. S. Leoutsakos, M. W. Johnson, and R. R. Griffiths. 2012. Factor analysis of the Mystical Experience Questionnaire: A study of experiences occasioned by the hallucinogen psilocybin. Journal for the Scientific Study of Religion 51(4): 721-37. doi: 10.1111/j.1468-5906.2012.01685.x

Mason, N. L., E. Mischler, M. V. Uthaug, and K. P. C. Kuypers. 2019. Sub-acute effects of psilocybin on empathy, creative thinking, and subjective well-being, Journal of Psychoactive Drugs 51(2): 123-34. doi:

10.1080/02791072.2019.1580804

Nour, M. M., L. Evans, and R. L. Carhart-Harris. 2017. Psychedelics, personality and political perspectives. Journal of Psychoactive Drugs 49(3): 182-91. doi: $10.1080 / 02791072.2017 .1312643$

Pahnke, W. N. 1963. Drugs and mysticism: An analysis of the relationship between psychedelic drugs and the mystical consciousness. Cambridge, MA: Harvard University Press.

Pahnke, W. N. 1969. The psychedelic mystical experience in the human encounter with death. Harvard Theological Review 62(1): 1-21. doi:

$10.1017 / \mathrm{S} 0017816000027577$

Palhano-Fontes, F., D. Barreto, H. Onias, K. C. Andrade, M. M. Novaes, J. A. Pessoa, S. A. Mota-Rolim, F. L. Osorio, R. Sanches, R. G. dos Santos, et al. 2019. Rapid antidepressant effects of the psychedelic ayahuasca in treatment-resistant depression: a randomized placebo-controlled trial. Psychological Medicine 49(4): 655-63. doi: 10.1017/S0033291718001356

Roseman, L., D. J. Nutt, and R. L. Carhart-Harris. 2018. Quality of acute psychedelic experience predicts therapeutic efficacy of psilocybin for treatment-resistant depression. Frontiers in Pharmacology 8: 974. doi: 10.3389/fphar.2017.00974

Ross, S., A. Bossis, J. Guss, G. Agin-Liebes, T. Malone, B. Cohen, S. E. Mennenga, A. Belser, K. Kalliontzi, J. Babb, et al. 2016. Rapid and sustained symptom reduction following psilocybin treatment for anxiety and depression in patients with life-threatening cancer: A randomized controlled trial. Journal of Psychopharmacology 30(12): 1165-80. doi: 10.1177/0269881116675512 
Rosseel, Y. 2012. lavaan: An R package for structural equation modeling. Journal of Statistical Software 48(2): 1-36. doi: 10.18637/jss.v048.i02

Revelle, W. 2017. psych: Procedures for personality and psychological research.. Available at https://CRAN.R-project.org/package=psych

Schmid, Y. and M. E. Liechti. 2018. Long-lasting subjective effects of LSD in normal subjects. Psychopharmacology 235(2): 535-45. doi: 10.1007/s00213-017-47333

Stace, W. T. 1960. Mysticism and philosophy. New York: MacMillan Press.

Strassman, R. 1984. Adverse reactions to psychedelic drugs. A review of the literature. The Journal of Nervous and Mental Disease, 172(10): 577-95. doi: 10.1097/00005053-198410000-00001

Tampere University. 2019. Ethical review on non-medical research in the field of the human sciences. Available at https://www.tuni.fi/en/research/responsibleresearch/ethical-reviews-in-human-sciences

Uthaug, M. V., R. Lancelotta, K. van Oorsouw, K.P. C. Kuypers, N. Mason, J. Rak,, A. Šuláková, R. Jurok, M. Maryška, M. Kuchař, et al. 2019. A single inhalation of vapor from dried toad secretion containing 5-methoxy-N,N-dimethyltryptamine (5-MeO-DMT) in a naturalistic setting is related to sustained enhancement of satisfaction with life, mindfulness-related capacities, and a decrement of psychopathological symptoms. Psychopharmacology. doi: 10.1007/s00213-01905236-w

Uthaug, M. V., K. van Oorsouw, K. P. C. Kuypers, M. van Boxtel, N. J. Broers, N. L. Mason, S. W. Toennes, J. Riba, and J. G. Ramaekers. 2018. Sub-acute and longterm effects of ayahuasca on affect and cognitive thinking style and their association with ego dissolution. Psychopharmacology 235(10): 2979-89. doi: 10.1007/s00213-018-4988-3

Wittmann, M., O. Carter, F. Hasler, B. R. Cahn, U. Grimberg, P. Spring, D. Hell, H. Flohr, and F. X. Vollenweider. 2007. Effects of psilocybin on time perception and temporal control of behaviour in humans. Journal of Psychopharmacology 21(1): 50-64. doi: 10.1177/0269881106065859

Xia, Y. 2016. Investigating the chi-square-based model-fit indexes for WLSMV and ULSMV estimators. PhD Diss., Florida State University. 
Table 1. Descriptive statistics on Finnish users of psychedelics and their first time using a psychedelic, for all participants and for those who did and did not experience a full mystical experience according to the Mystical Experiences Questionnaire.

\begin{tabular}{|c|c|c|c|c|c|c|}
\hline & \multicolumn{2}{|c|}{$\begin{array}{l}\text { Total sample } \\
\qquad(N=288)\end{array}$} & \multicolumn{2}{|c|}{$\begin{array}{c}\text { Full mystical } \\
\text { experience }(n=77)\end{array}$} & \multicolumn{2}{|c|}{$\begin{array}{c}\text { No full mystical } \\
\text { experience }(n=211)\end{array}$} \\
\hline & $n$ & $\%$ & $n$ & $\%$ & $n$ & $\%$ \\
\hline \multicolumn{7}{|l|}{ Gender } \\
\hline Male & 110 & 38.2 & 31 & 40.3 & 79 & 37.4 \\
\hline Female & 164 & 56.9 & 42 & 54.5 & 122 & 57.8 \\
\hline Other / NA & 14 & 4.9 & 4 & 5.2 & 10 & 4.7 \\
\hline \multicolumn{7}{|l|}{ Age } \\
\hline $18-23$ & 76 & 26.4 & 19 & 24.7 & 57 & 27.0 \\
\hline $24-29$ & 100 & 34.7 & 29 & 37.7 & 71 & 33.6 \\
\hline $30-35$ & 58 & 20.1 & 17 & 22.1 & 41 & 19.4 \\
\hline $36-41$ & 36 & 12.5 & 9 & 11.7 & 27 & 12.8 \\
\hline $42-47$ & 10 & 3.5 & 1 & 1.3 & 9 & 4.3 \\
\hline $48-$ & 8 & 2.8 & 2 & 2.6 & 6 & 2.8 \\
\hline \multicolumn{7}{|l|}{ Current education } \\
\hline Basic education & 20 & 6.9 & 7 & 9.1 & 13 & 6.1 \\
\hline $\begin{array}{l}\text { High school or } \\
\text { vocational school }\end{array}$ & 124 & 43.1 & 32 & 41.6 & 92 & 43.6 \\
\hline Special vocational & 10 & 3.5 & 2 & 2.6 & 8 & 3.8 \\
\hline Undergraduate & 79 & 27.4 & 27 & 35.1 & 52 & 24.6 \\
\hline Graduate/postgraduate & 54 & 18.8 & 9 & 11.7 & 45 & 21.3 \\
\hline Other & 1 & 0.3 & 0 & 0 & 1 & 0.5 \\
\hline \multicolumn{7}{|l|}{$\begin{array}{l}\text { Times used } \\
\text { psychedelics }\end{array}$} \\
\hline 1 & 14 & 4.9 & 4 & 5.2 & 10 & 4.7 \\
\hline 2 & 10 & 3.5 & 1 & 1.3 & 9 & 4.3 \\
\hline $3-5$ & 51 & 17.7 & 10 & 13 & 41 & 19.4 \\
\hline $6-10$ & 59 & 20.5 & 14 & 18.2 & 45 & 21.3 \\
\hline $11-50$ & 123 & 42.7 & 36 & 46.8 & 87 & 41.2 \\
\hline $51-$ & 31 & 10.8 & 12 & 15.6 & 19 & 9.0 \\
\hline
\end{tabular}


Table 1. (Continued)

\begin{tabular}{|c|c|c|c|c|c|c|}
\hline & \multicolumn{2}{|c|}{$\begin{array}{l}\text { Total sample } \\
(N=288)\end{array}$} & \multicolumn{2}{|c|}{$\begin{array}{c}\text { Full mystical } \\
\text { experience }(n=77)\end{array}$} & \multicolumn{2}{|c|}{$\begin{array}{c}\text { No full mystical } \\
\text { experience }(n=211)\end{array}$} \\
\hline & $n$ & $\%$ & $n$ & $\%$ & $n$ & $\%$ \\
\hline \multicolumn{7}{|l|}{ Time since experience } \\
\hline $0-6$ months & 20 & 6.9 & 3 & 3.9 & 17 & 8.1 \\
\hline $7-12$ months & 13 & 4.5 & 2 & 2.6 & 11 & 5.2 \\
\hline 13-24 months & 30 & 10.4 & 7 & 9.1 & 23 & 10.9 \\
\hline $2-5$ years & 101 & 35.1 & 29 & 37.7 & 72 & 34.1 \\
\hline $5-10$ years & 78 & 27.1 & 26 & 33.8 & 52 & 24.6 \\
\hline Over 10 years & 46 & 16.0 & 10 & 13 & 36 & 17.1 \\
\hline \multicolumn{7}{|l|}{ Psychedelic used } \\
\hline LSD & 128 & 44.4 & 37 & 48.1 & 91 & 43.1 \\
\hline $\begin{array}{l}\text { LSA or LSA-containing } \\
\text { seeds }\end{array}$ & 8 & 2.8 & 1 & 1.3 & 7 & 3.3 \\
\hline $\begin{array}{l}\text { Psilocybin or psilocybin- } \\
\text { containing mushrooms }\end{array}$ & 133 & 46.2 & 33 & 42.9 & 100 & 47.4 \\
\hline DMT & 1 & 0.3 & 0 & 0.0 & 1 & 0.5 \\
\hline Ayahuasca & 7 & 2.4 & 1 & 1.3 & 6 & 2.8 \\
\hline Other & 11 & 3.8 & 5 & 6.5 & 6 & 2.8 \\
\hline \multicolumn{7}{|l|}{ Approximate dose } \\
\hline Very small & 5 & 1.7 & 0 & 0.0 & 5 & 2.4 \\
\hline Smaller than typical & 60 & 20.8 & 8 & 10.4 & 52 & 24.6 \\
\hline Typical & 173 & 60.1 & 49 & 63.6 & 124 & 58.8 \\
\hline Larger than typical & 38 & 13.2 & 16 & 20.8 & 22 & 10.4 \\
\hline Very large & 9 & 3.1 & 3 & 3.9 & 6 & 2.8 \\
\hline Cannot say & 3 & 1.0 & 1 & 1.3 & 2 & 0.9 \\
\hline \multicolumn{7}{|l|}{ Location of use } \\
\hline Home & 93 & 32.3 & 21 & 27.3 & 72 & 34.1 \\
\hline Friend's home & 95 & 33.0 & 32 & 41.6 & 63 & 29.9 \\
\hline Unknown person's home & 6 & 2.1 & 2 & 2.6 & 4 & 1.9 \\
\hline Nature & 55 & 19.1 & 14 & 18.2 & 41 & 19.4 \\
\hline Public space & 18 & 6.3 & 3 & 3.9 & 15 & 7.1 \\
\hline Other & 21 & 7.3 & 5 & 6.5 & 16 & 7.6 \\
\hline
\end{tabular}


Table 1. (Continued)

\begin{tabular}{|c|c|c|c|c|c|c|}
\hline & \multicolumn{2}{|c|}{$\begin{array}{l}\text { Total sample } \\
\quad(N=288)\end{array}$} & \multicolumn{2}{|c|}{$\begin{array}{c}\text { Full mystical } \\
\text { experience }(n=77)\end{array}$} & \multicolumn{2}{|c|}{$\begin{array}{c}\text { No full mystical } \\
\text { experience }(n=211)\end{array}$} \\
\hline & $n$ & $\%$ & $n$ & $\%$ & $n$ & $\%$ \\
\hline \multicolumn{7}{|l|}{ Primary context for use } \\
\hline Relaxed hanging around & 144 & 50.0 & 31 & 40.3 & 113 & 53.6 \\
\hline Healing session & 57 & 19.8 & 22 & 28.6 & 35 & 16.6 \\
\hline Private party & 22 & 7.6 & 8 & 10.4 & 14 & 6.6 \\
\hline Concert or festival & 19 & 6.6 & 4 & 5.2 & 15 & 7.1 \\
\hline Other & 46 & 16.0 & 12 & 15.6 & 34 & 16.1 \\
\hline \multicolumn{7}{|l|}{ People present } \\
\hline Alone & 19 & 6.6 & 6 & 7.8 & 13 & 6.2 \\
\hline One other person & 106 & 36.8 & 27 & 35.1 & 79 & 37.4 \\
\hline $\begin{array}{l}\text { Several people, all } \\
\text { familiar }\end{array}$ & 122 & 42.4 & 31 & 40.3 & 91 & 43.1 \\
\hline $\begin{array}{l}\text { Several people, some } \\
\text { unfamiliar }\end{array}$ & 41 & 14.2 & 13 & 16.9 & 28 & 13.3 \\
\hline
\end{tabular}


Table 2. Self-evaluated quality of the experience and changes experienced in well-being in the weeks and months after, among people reporting on the first time they used a psychedelic in Finland, for all participants and for those who did and did not experience a full mystical experience according to the Mystical Experiences Questionnaire.

\begin{tabular}{|c|c|c|c|c|c|c|c|}
\hline & $\begin{array}{l}\text { Total sample } \\
\qquad(N=288)\end{array}$ & $\begin{array}{l}\text { Full mystical } \\
\text { experience } \\
(n=77)\end{array}$ & $\begin{array}{l}\text { No mystical } \\
\text { experience } \\
(n=211)\end{array}$ & & & & \\
\hline & $M(S D)$ & $M(S D)$ & $M(S D)$ & $t$ & df & $p$ & $g$ \\
\hline \multicolumn{8}{|l|}{ Changes after psychedelic use } \\
\hline Life satisfaction and well-being & $5.45(1.29)$ & $5.88(1.40)$ & $5.30(1.22)$ & 3.25 & 120.87 & .0015 & 0.45 \\
\hline Mental health & $4.99(1.28)$ & $5.36(1.38)$ & $4.86(1.22)$ & 2.84 & 122.42 & .0052 & 0.39 \\
\hline Physical health & $4.28(0.78)$ & $4.61(1.03)$ & $4.17(0.64)$ & 3.55 & 98.09 & .0006 & 0.64 \\
\hline Creativity & $5.07(1.04)$ & $5.66(1.11)$ & $4.85(0.93)$ & 5.75 & 117.22 & $<.0001$ & 0.82 \\
\hline Cognitive skills and memory & $4.32(0.83)$ & $4.81(1.09)$ & $4.15(0.63)$ & 5.01 & 95.46 & $<.0001$ & 0.84 \\
\hline Nature relationship & $5.28(1.11)$ & $5.99(1.06)$ & $5.03(1.02)$ & 6.87 & 131.25 & $<.0001$ & 0.93 \\
\hline Relationship with others & $5.01(1.10)$ & $5.48(1.06)$ & $4.84(1.07)$ & 4.50 & 136.69 & $<.0001$ & 0.60 \\
\hline Relationship with self & $5.39(1.23)$ & $5.95(1.18)$ & $5.19(1.19)$ & 4.82 & 135.92 & $<.0001$ & 0.64 \\
\hline \multicolumn{8}{|l|}{ Quality of the experience } \\
\hline Mystical, spiritual, or religious & $3.01(1.37)$ & $4.08(1.01)$ & $2.63(1.28)$ & 10.02 & 169.89 & $<.0001$ & 1.19 \\
\hline Personally significant & $4.22(1.01)$ & $4.79(0.47)$ & $4.01(1.07)$ & 8.59 & 277.54 & $<.0001$ & 0.82 \\
\hline Fun & $3.81(1.15)$ & $3.96(1.09)$ & $3.76(1.17)$ & 1.37 & 143.50 & .174 & 0.17 \\
\hline Sad & $1.95(1.14)$ & $2.25(1.3)$ & $1.84(1.06)$ & 2.44 & 115.26 & .016 & 0.36 \\
\hline Easy & $3.65(1.19)$ & $3.30(1.21)$ & $3.78(1.15)$ & 3.03 & 129.3 & .003 & 0.41 \\
\hline Pleasant & $4.20(1.17)$ & $4.38(1.00)$ & $4.14(1.22)$ & 1.69 & 163.02 & .093 & 0.21 \\
\hline
\end{tabular}

Note. Means and standard deviations presented. Results of Welch's $t$ test presented. Hedges' $g_{\mathrm{s}}$ presented as measure of effect size.

Higher scores indicate more positive changes / more of the quality in question. 
Table 3. Fit statistics for four different possible factor structures of the Finnish version of the Revised Mystical Experiences Questionnaire, as tested among people reporting on their first time using a psychedelic in Finland.

\begin{tabular}{|c|c|c|c|c|c|c|}
\hline$\underline{\text { Model }}$ & $\underline{\mathrm{CFI}}$ & $\underline{\text { TLI }}$ & $\underline{\text { RMSEA }}$ & $\underline{\text { SRMR }}$ & $\chi^{2}$ & $\underline{\mathrm{df}}$ \\
\hline Four-factor model & .939 & .933 & .084 & .068 & 1209.42 & 399 \\
\hline Hood model & .902 & .893 & .106 & .083 & 1700.35 & 402 \\
\hline Stace model & .904 & .896 & .105 & .083 & 1668.06 & 402 \\
\hline Single-factor model & .894 & .886 & .110 & .087 & 1800.32 & 405 \\
\hline
\end{tabular}




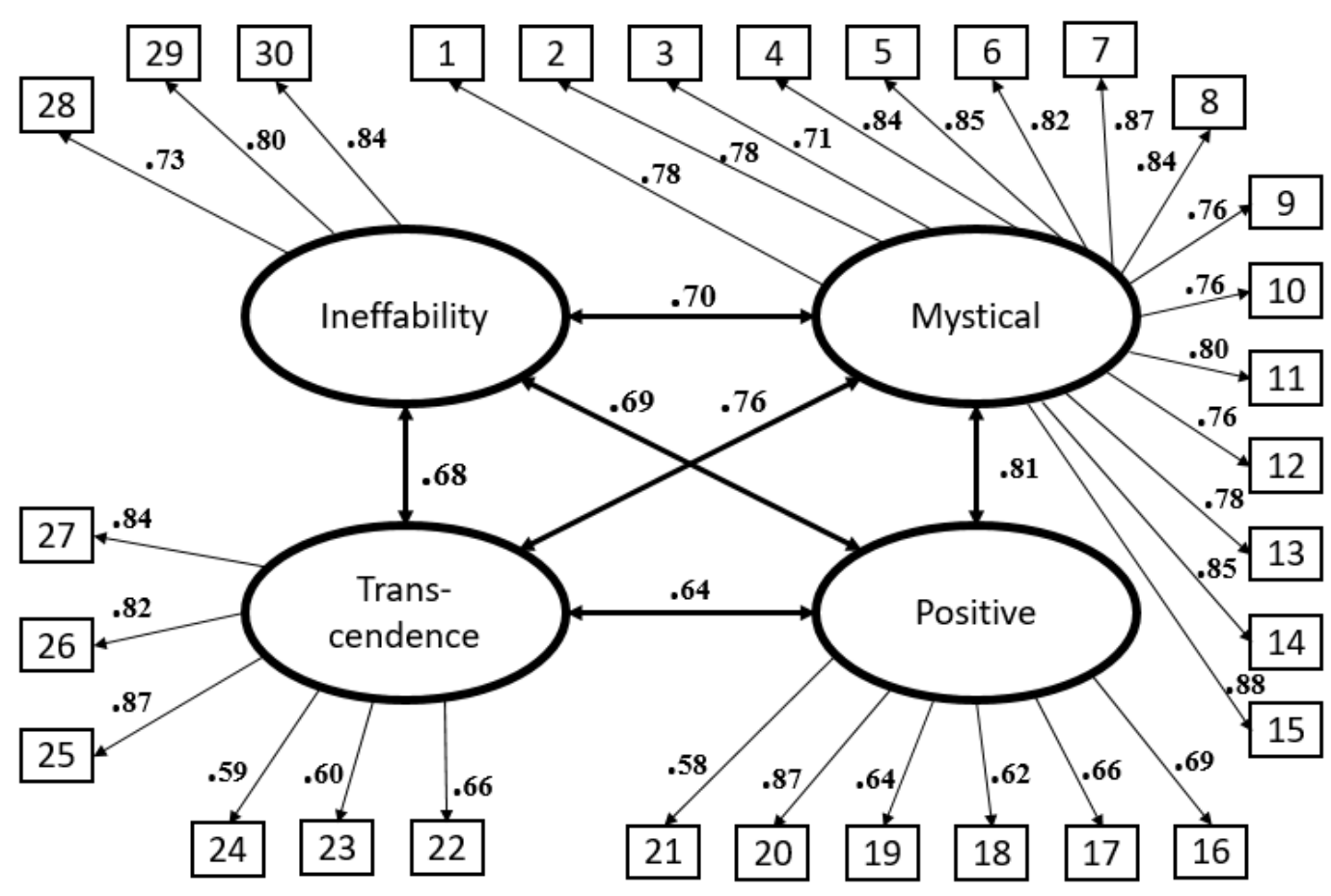

Figure 1. Factor loadings and covariances between the factors for best-fitting four-factor model for the Finnish version of the Revised Mystical Experiences Questionnaire among people reporting on the first time they used a psychedelic in Finland. All loadings significant at $p<.001$. Residual variances omitted for clarity. $N=288$. 
Supplementary Table 1. Fit statistics for four different possible factor structures of the Finnish version of the Revised Mystical Experiences Questionnaire, as tested among first time users of psychedelics in Finland. Alternative analysis using maximum likelihood estimation.

\begin{tabular}{|c|c|c|c|c|c|c|}
\hline$\underline{\text { Model }}$ & $\underline{\mathrm{CFI}}$ & $\underline{\text { TLI }}$ & $\underline{\text { RMSEA }}$ & $\underline{\text { SRMR }}$ & $\chi^{2}$ & $\underline{\mathrm{df}}$ \\
\hline Four-factor model & 0.877 & 0.866 & 0.076 & 0.067 & 974.59 & 399 \\
\hline Hood model & 0.819 & 0.805 & 0.092 & 0.075 & 1244.92 & 402 \\
\hline Stace model & 0.822 & 0.808 & 0.092 & 0.074 & 1230.78 & 402 \\
\hline Single-factor model & 0.799 & 0.784 & 0.097 & 0.078 & 1337.81 & 405 \\
\hline
\end{tabular}


Supplementary Figure 1. Latent variable model of mystical experiences among Finnish first-time users of psychedelics and their links with self-perceived changes in different areas of well-being. Fully standardized parameter estimates presented.

Covariances between different types of changes and residual variances omitted for clarity. $N=288$.

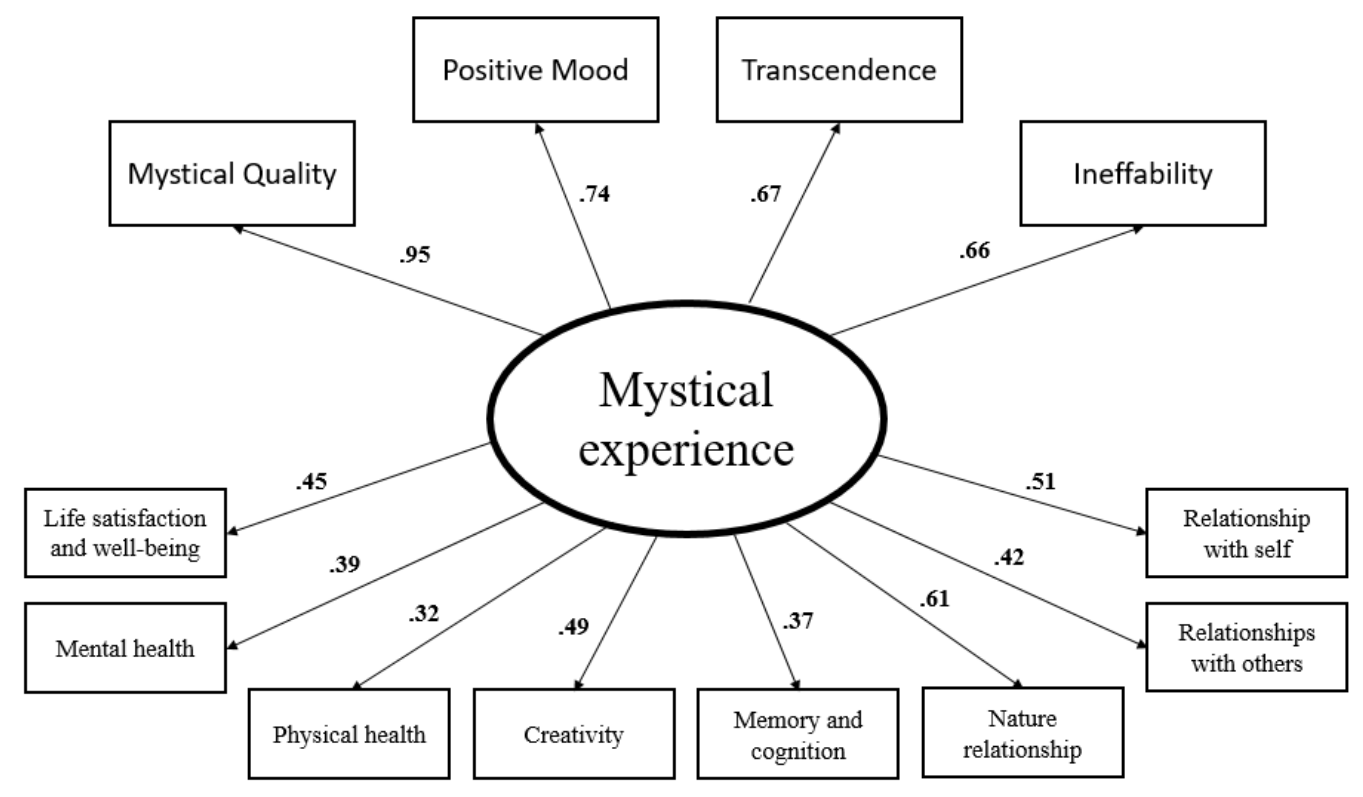

